\title{
pH gradients through colonies of Bacillus cereus and the surrounding agar
}

\author{
T. P. Robinson, ${ }^{1 *}$ J. W. T. WIMPENNY ${ }^{1}$ and R. G. EARNSHAW ${ }^{2}$ \\ ${ }^{1}$ School of Pure and Applied Biology, University of Wales College of Cardiff, Cardiff CF1 3TL, UK \\ ${ }^{2}$ Campden Food and Drink Research Association, Chipping Campden GL55 6LD, UK
}

(Received 19 June 1991; revised 21 August 1991; accepted 29 August 1991)

\begin{abstract}
pH-sensitive microelectrodes, constructed with a tip diameter of about $4 \mu \mathrm{m}$, were deployed through $24 \mathrm{~h}$ and $48 \mathrm{~h}$ colonies of Bacillus cereus incubated on CYS medium (Casamino acids, yeast extract, salts), with and without glucose. Measurements of $\mathrm{pH}$ were used to construct $\mathrm{pH}$ profiles through the colony and the surrounding agar. $\mathrm{pH}$ gradients could be detected for at least $800 \mu \mathrm{m}$ into the agar beneath a $24 \mathrm{~h}$ colony, and to approximately $10 \mathrm{~mm}$ horizontally away from the edge of the colony. In older colonies, the lateral gradient extended for over $20 \mathrm{~mm}$. The $\mathrm{pH}$ of the underlying agar was increased by up to $1.45 \mathrm{pH}$ units after $48 \mathrm{~h}$ growth without glucose. When colonies were grown with glucose, a significant area of acidification was observed within the colony in addition to a zone of alkalinization present at its periphery. Acidification was thought to be due to the anaerobic fermentation of glucose producing organic acids whilst alkalinization was due to the aerobic oxidation of amino acids releasing ammonia.
\end{abstract}

\section{Introduction}

Bacteria growing on the surface of agar will deplete the nutrients immediately adjacent to the colony (Pirt, 1967). This will lead to the production of steep solute gradients beneath the growing colony. Rieck et al. (1973) demonstrated that the growth rate of colonies of Pseudomonas fluorescens became limited by the rate of diffusion of glucose when grown on glucose/salts agar containing low concentrations of glucose. In addition, under aerobic conditions, oxygen will diffuse downwards into a colony (Pirt, 1967; Wimpenny \& Lewis, 1977). Gradients of oxygen penetration through colonies of Bacillus cereus have been measured directly (Wimpenny \& Coombs, 1983). The results showed that an anaerobic zone is formed in the centre of an $18 \mathrm{~h} \mathrm{~B}$. cereus colony, incubated at $30^{\circ} \mathrm{C}$. Since $B$. cereus is a facultative anaerobe there is the possibility that cells at the centre of the colony were growing anaerobically and producing organic acids. Kamath \& Bungay (1988) also observed that colonies of aerobic species growing on solid media containing glucose receive glucose from the medium below, while oxygen diffuses from the gaseous phase above. The counter-diffusion and uptake of these two species means that there is a possibility that in certain regions, metabolism is limited to oxygen availability while in others, glucose is lacking. This would imply that

Abbreviation: LIX, liquid ion-exchange. there is a significant degree of physicochemical heterogeneity within a colony. This in turn could give rise to the cells in different areas of a colony having different metabolic activities. Cooper et al. (1968) postulated that the active growth of a colony is confined to an annulus at the colony margin. Shapiro $(1984,1987)$ demonstrated that bacterial colonies have a high degree of morphological and biochemical organization, and showed that colonies of Escherichia coli expand by the addition of cells only at the periphery. This heterogeneity within a colony might cause characteristic $\mathrm{pH}$ gradients to be formed through and around the growing colony.

There are a number of processes which can lead to $\mathrm{pH}$ changes. These include the fermentation of carbohydrates to organic acids, so lowering the $\mathrm{pH}$, the complete oxidation of organic acids or the oxidation of amino acids leading to an accumulation of ammonia, both processes leading to a rise in $\mathrm{pH}$. The alteration of $\mathrm{pH}$ by the growth of bacteria in liquid batch culture is well documented (Spira \& Silverman, 1979; Weimer, 1984). It is suggested that these processes could lead to the formation of $\mathrm{pH}$ gradients through a growing colony and into the agar beneath it.

The ability of micro-organisms to alter the $\mathrm{pH}$ in their locality, so producing a microenvironment of different $\mathrm{pH}$, is of particular interest to the food industry. Food preserved by a low $\mathrm{pH}$ may become compromised by the growth of 'harmless' spoilage organisms raising the local $\mathrm{pH}$. Food-poisoning organisms which would otherwise 
be inhibited may then grow in these microenvironments. The presence of such microenvironments would not be detected by crude $\mathrm{pH}$ measurements.

Microelectrodes were originally designed for physiological studies of higher animals (Caldwell, 1954; Hinke, 1959). More recently they have been applied in microbial ecology (Revsbech \& Jørgensen, 1986). pH gradients have been measured through complex microbial aggregations such as cyanobacterial mats (Jørgensen et al., 1983; Revsbech \& Ward, 1984), marine sediments and algal mats containing colourless sulphur bacteria (Jørgensen \& Revsbech, 1983; Nelson et al., 1986) and dental plaque (Brown et al., 1981). By using microelectrodes it has been possible to measure the $\mathrm{pH}$ heterogeneity of these systems with a high degree of spatial resolution.

In the experiments described below, microelectrodes were used to determine $\mathrm{pH}$ profiles in colonies of $\boldsymbol{B}$. cereus growing in air on an amino-acid-containing medium in the presence and absence of glucose.

\section{Methods}

Organisms, maintenance and media. Bacillus cereus CRA 666 was obtained from the Campden Food and Drink Research Association. The bacteria were stored as vegetative cells, on glass beads at $-70^{\circ} \mathrm{C}$ (Jones et al., 1984) and maintained at $30^{\circ} \mathrm{C}$ on nutrient agar containing ( $\mathrm{g}^{-1}$ in distilled water): nutrient broth (Difco), 8.0; Bacto-agar (Difco), 15.0. The inoculum was prepared by streaking a plate of the appropriate medium with $B$. cereus and incubating at $30^{\circ} \mathrm{C}$ for $24 \mathrm{~h}$. The medium used (CYS) contained ( $\mathrm{g}^{-1}$ in distilled water): Casamino acids (Difco), 5.0 ; yeast extract (Difco), 2.0 ; plus salts solution, $5.0 \mathrm{ml}$ $1^{-1}$. The salts solution contained $\left(\mathrm{g} \mathrm{l}^{-1}\right): \mathrm{MgSO}_{4} .7 \mathrm{H}_{2} \mathrm{O}, 10.0$; $\mathrm{MnCl}_{2} .4 \mathrm{H}_{2} \mathrm{O}, 1 \cdot 0 ; \mathrm{FeSO}_{4} \cdot 7 \mathrm{H}_{2} \mathrm{O}, 0.4 ; \mathrm{CaCl}_{2} .6 \mathrm{H}_{2} \mathrm{O}, 0.2$, plus a few drops of concentrated $\mathrm{HCl}$ to clarify the solution. This medium, with (CYSG) or without (CYS) $10 \mathrm{~g}$ glucose $1^{-1}$, was solidified with $15 \mathrm{~g}$ Bacto-agar (Difco) $1^{-1}$. The salts solution and the glucose were sterilized separately and added to the sterile medium before pouring. Plates containing $20 \mathrm{ml}$ medium were dried at $37^{\circ} \mathrm{C}$ for $1-1.5 \mathrm{~h}$. The $\mathrm{pH}$ of the agar was then measured using a flat-ended $\mathrm{pH}$ combination electrode (no. 91655C, Orion Research UK).

Inoculation procedure. The agar plates were inoculated using a glass needle drawn out from a Pasteur pipette. The tip of the needle was used to transfer cells by placing it onto the surface of a colony and then onto the surface of the sterile agar, without penetrating it. Each plate was inoculated once, at its centre.

Electrode construction and deployment. $\mathrm{pH}$-sensitive liquid ionexchange (LIX) microelectrodes with a tip diameter of $2 \cdot 5-6.0 \mu \mathrm{m}$ were constructed using a method similar to that described by Walker (1971) and Bertl et al. (1984). Glass micropipettes with a tip diameter of 2.5$6.0 \mu \mathrm{m}$ were pulled from $2 \mathrm{~mm}$ outside-diameter borosilicate glass (Clark Electromedical Instruments) using a homemade vertical glass puller, as described by Thomas (1978). If necessary the tip of the micropipette was removed to ensure that an unrestricted hole was present. This was achieved by holding the micropipette vertically with a micromanipulator. A second micromanipulator was then employed to position a metal bar directly beneath the downward-pointing micropipette. The micropipette was lowered on to the metal bar and the bench was given a light tap. This provided enough vibration to break the tip of the micropipette. The whole operation was observed through a horizontally mounted microscope. The tip of the glass was then made hydrophobic by dipping it into a solution of $0.2 \%(\mathrm{v} / \mathrm{v})$ dimethyldichlorosilane in benzene, so that the solution was drawn up approximately $200 \mu \mathrm{m}$ into the tip by capillary action. The pipette was then placed in an oven at $90{ }^{\circ} \mathrm{C}$ for at least $90 \mathrm{~min}$. Prepared micropipettes were stored in a desiccator for up to one week. Liquid ion-exchanger (ionophore no. 95297, Fluka Chemicals) was drawn into the hydrophobic tip by capillary action. The electrode was then backfilled with $1 \mathrm{M}$ $\mathrm{KCl}$, by using a plastic $1 \mathrm{ml}$ syringe that had been heated and pulled to a fine point. The air between the ion-exchanger and the $\mathrm{KCl}$ was removed by inserting a cat's whisker into the electrode until it just touched the surface of the ion-exchanger. The $\mathrm{KCl}$ solution ran down the whisker and displaced the air. Any remaining air bubbles were dislodged by gently tapping the side of the electrode. Electrical connection to the $\mathrm{KCl}$ was made with a $\mathrm{Ag} / \mathrm{AgCl}$ wire. The electrode was aged by placing it in potassium phosphate buffer $\mathrm{pH} 7.0$ for $3 \mathrm{~h}$. It could then be calibrated by placing the electrode in CYS broth that had been adjusted to $\mathrm{pH}$ values over the range $4 \cdot 0-8 \cdot 0$. A second $\mathrm{Ag} / \mathrm{AgCl}$ wire was used as the reference electrode. Electrodes with a drift of more than $5 \mathrm{mV} \mathrm{h}^{-1}$ were discarded, as were electrodes that took longer than $3 \mathrm{~min}$ to give a stable response in buffer solutions.

The $\mathrm{pH}$ was measured through a colony by mounting a $\mathrm{pH}$-sensitive microelectrode on a Prior micromanipulator. The Petri dish was placed on a level board and the electrode was lowered at measured intervals from one side of the colony to the other. The microelectrode and the $\mathrm{Ag} / \mathrm{AgCl}$ reference electrode were attached to a Dulas Engineering $\mathrm{pH}$ meter, which was in turn connected to a chart recorder. The electrodes were deployed in a Faraday cage to reduce electrical noise.

\section{Results and Discussion}

The LIX electrode typically gave a linear response of 56 $\mathrm{mV}$ per $\mathrm{pH}$ unit over the range $\mathrm{pH} 4-8$, compared to the theoretical response at $20^{\circ} \mathrm{C}$ of about $58.1 \mathrm{mV}$ per $\mathrm{pH}$ unit. The response range of the LIX was found to be $\mathrm{pH}$ 2.0-8.8.

The $\mathrm{pH}$ of the CYS medium was $6.13 \pm 0.02$ and that of the CYSG medium was $6 \cdot 15 \pm 0.03$. The diameters of the colonies examined were $5.2 \mathrm{~mm}$ and $16.5 \mathrm{~mm}$ for the $24 \mathrm{~h}$ and $48 \mathrm{~h}$ CYS colonies and $4.4 \mathrm{~mm}$ and $19 \mathrm{~mm}$ for the $24 \mathrm{~h}$ and $48 \mathrm{~h} \mathrm{CYSG}$ colonies, respectively (only one colony from each growth condition was measured). Colonies grown without glucose were dome shaped,

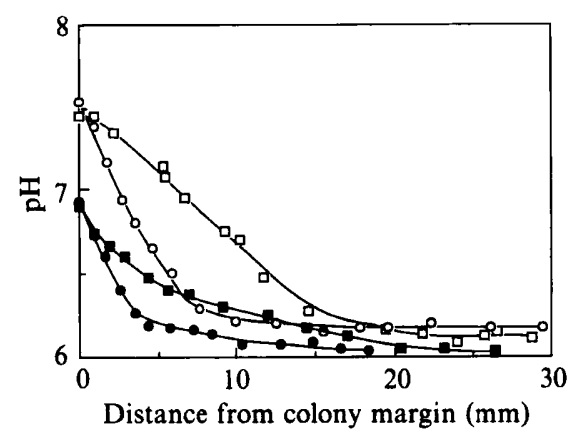

Fig. 1. The pH at the surface of the agar, plotted against increasing distance from the colony margin, for $24 \mathrm{~h} \mathrm{CYS} \mathrm{(O),} 48 \mathrm{~h} \mathrm{CYS}(O), 24 \mathrm{~h}$ CYSG ( $\square$ ) and $48 \mathrm{~h}$ CYSG ( $\square$ ) B. cereus colonies. 

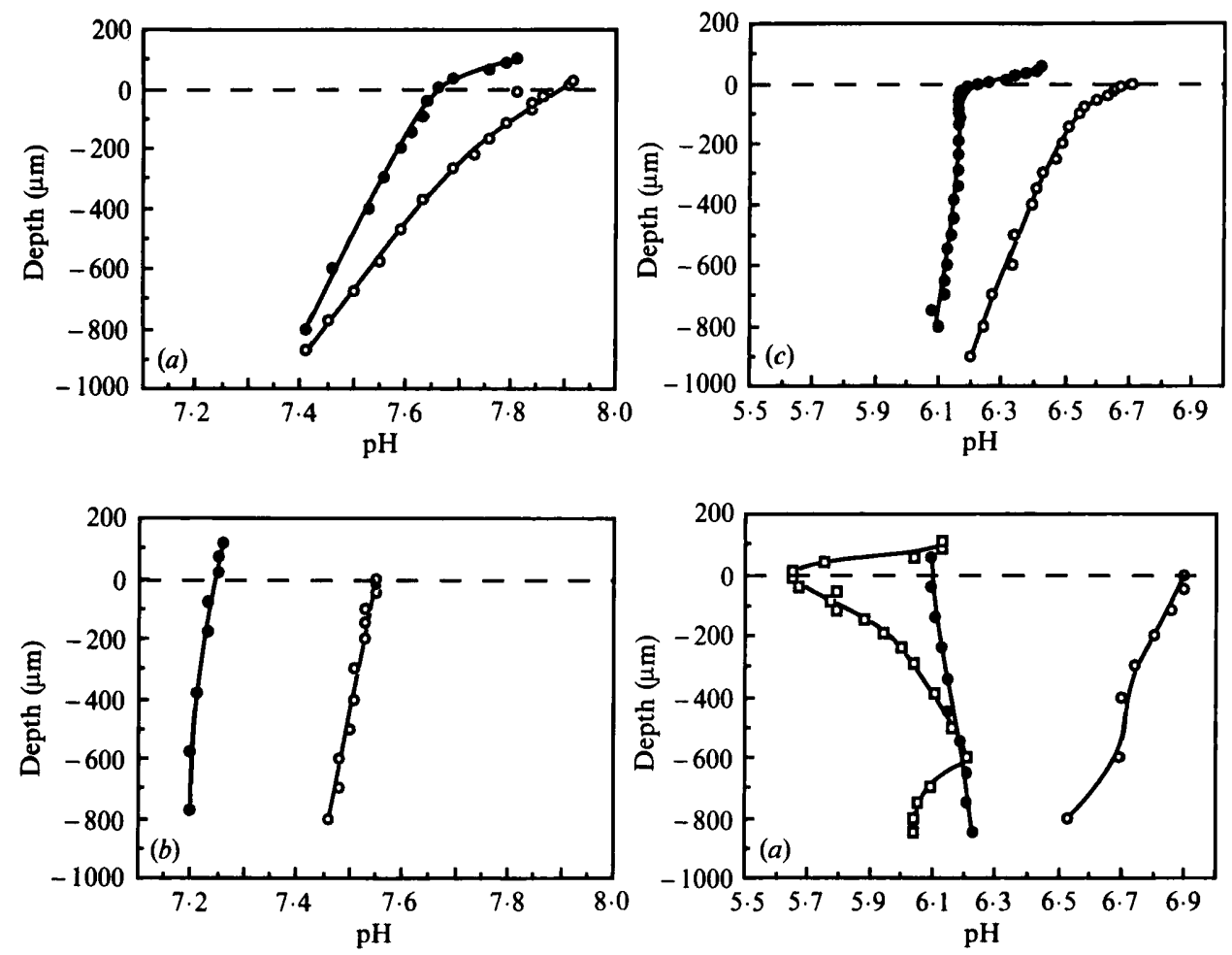

Fig. 2. Vertical pH profiles through the centre $(O)$ and margin $(O)$ of $(a)$ a $24 \mathrm{~h} B$. cereus colony grown without glucose, $(b)$ a $48 \mathrm{~h} B$. cereus colony grown without glucose, $(c)$ a $24 \mathrm{~h} B$. cereus colony grown with glucose, and $(d)$ the centre $(O)$, margin $(O)$ and acid region $(\square)$ of a $48 \mathrm{~h} \mathrm{~B}$. cereus colony grown with glucose. The dashed line indicates the surface of the agar.

whilst those grown with glucose had a more complex profile. Of the latter, the young colonies had surfaces showing a ridged appearance, whilst the older colonies had formed a thickened ring just within the periphery. This ring had a smooth and mucoid appearance whilst the colony surface on either side of this region had a rough appearance.

The $\mathrm{pH}$ at the surface of the agar was shown in all cases to decrease with increasing distance from the colony margin (Fig. 1), i.e. the colony had an overall alkalinization effect on the surrounding medium. The maximum distance, affected by each colony was approximately $10 \mathrm{~mm}$ for the $24 \mathrm{~h}$ colonies and $20 \mathrm{~mm}$ for the $48 \mathrm{~h}$ colonies. The presence of glucose had no significant effect on this. The $\mathrm{pH}$ gradient formed was steeper in both cases for the $24 \mathrm{~h}$ colonies.

Vertical $\mathrm{pH}$ gradients through the centre and margin of the colonies were plotted (Fig, $2 a-d$ ). In all cases the $\mathrm{pH}$ at the margin of the colony was greater than the $\mathrm{pH}$ at the centre. The $\mathrm{pH}$ gradients were steepest under the younger colonies and at the surface of the agar, through and immediately adjacent to the colony. The $\mathrm{pH}$ gradient through a region near the colony periphery (see Fig. $3 d$ ) of the $48 \mathrm{~h}$ CYSG colony was also plotted (Fig. $2 d$ ). This showed that there was a region of acid production adjacent to the surface of the agar.

$\mathrm{pH}$ values measured through the colonies and the surrounding agar were mapped as $\mathrm{pH}$ isopleths. Only half colonies were plotted for the $48 \mathrm{~h}$ colonies, to enable more detail to be displayed. Each point on the maps indicates where a $\mathrm{pH}$ measurement was taken. The young $(24 \mathrm{~h})$ colony grown without glucose increased the $\mathrm{pH}$ of the underlying medium by up to 1.8 units, to a maximum of 7.92 (Fig. $3 a$ ). The alkalinization occurred throughout the whole colony. After $48 \mathrm{~h}$ (Fig. $3 b$ ), the maximum $\mathrm{pH}$ recorded was 7.6. In this older colony, a region of greater activity at the colony margin could be discerned. It was thought that the reduced activity in the centre of the colony was due to growth in that region being diffusion limited.

The $24 \mathrm{~h}$ colony grown with glucose (Fig. $3 c$ ) also showed an overall alkalinization, with a maximum $\mathrm{pH}$ of 6.78. A pronounced edge effect was detected where the highest $\mathrm{pH}$ values were recorded, with lower values (pH 6.26) in the centre of the colony. This effect was thought to be due to anaerobiosis at the centre of the colony (Peters et al., 1987). This would lead to the fermentative production of organic acids from glucose, 

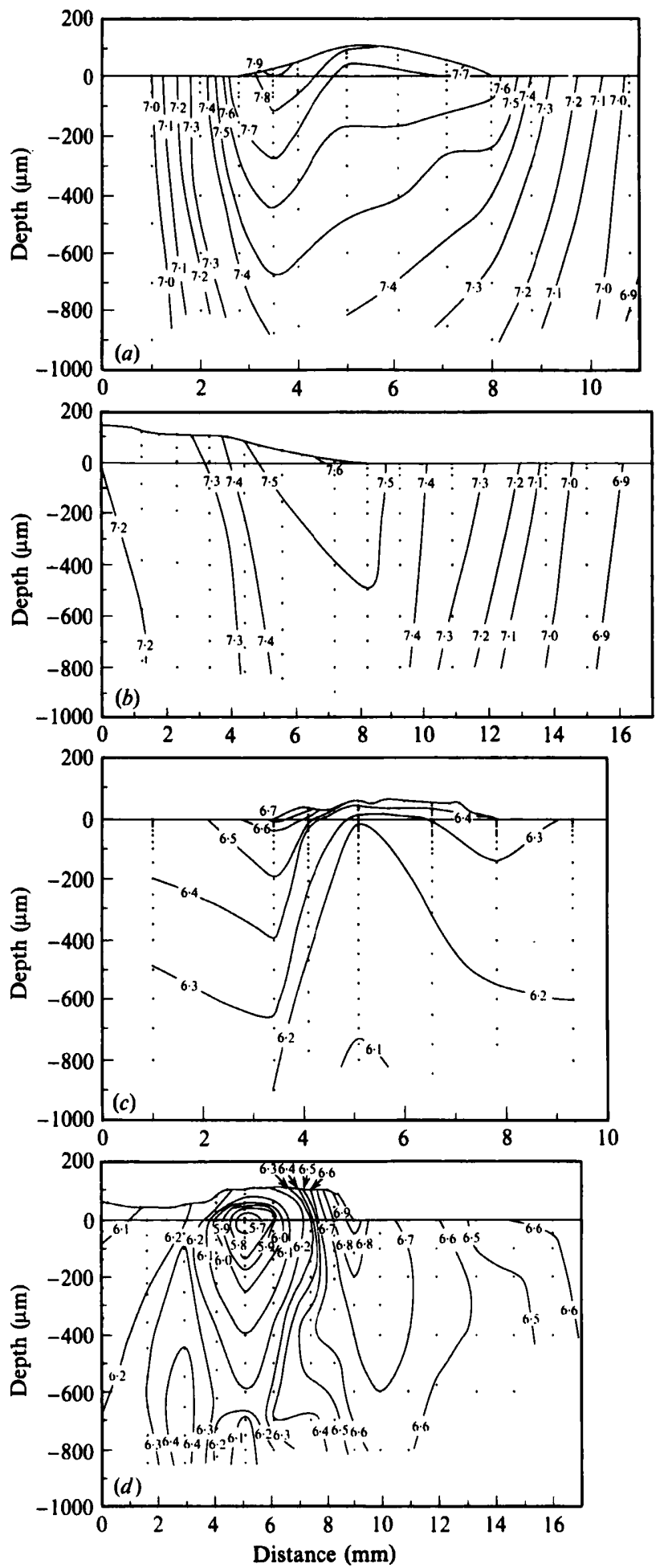

Fig. 3. pH profiles of $B$. cereus colonies (a) $24 \mathrm{~h}$, without glucose, (b) $48 \mathrm{~h}$ without glucose, (c) $24 \mathrm{~h}$ with glucose, (d) $48 \mathrm{~h}$ with glucose.

causing a fall in pH. After $48 \mathrm{~h}$ (Fig. $3 d$ ), the most pronounced alkalinization was again at the colony margin (pH 6.90). A region of acidification (minimum $\mathrm{pH} 5.65$ ) occurred centring on a region $3-4 \mathrm{~mm}$ in from the colony margin, adjacent to the surface of the agar. Between these two regions there was a steep $\mathrm{pH}$ gradient. The centre of the colony was more alkaline than the acidic region but less alkaline than the colony margin.

The asymmetry shown by the two $24 \mathrm{~h}$ colonies was thought to be due to the time taken to measure the whole profile (approx. $6 \mathrm{~h}$ ). The colonies were incubated at $30^{\circ} \mathrm{C}$ and measured at room temperature (about $22^{\circ} \mathrm{C}$ ). The reduction in microbial activity at the lower temperature was thought to be responsible for the apparent difference in $\mathrm{pH}$ pattern from one side of the colony to the other. The $24 \mathrm{~h}$ colonies were measured from left to right.

It seems likely that $\mathrm{pH}$ changes on CYSG, which contains glucose as well as amino acids, are the products of two processes. First, in the presence of excess glucose and when the cells are anoxic, anaerobic fermentation reactions lead to the formation of organic acids and a fall in $\mathrm{pH}$. Other measurements in gel-stabilized cultures of B. cereus (Coombs \& Wimpenny, 1982) indicate that this organism can lower the $\mathrm{pH}$ to $5 \cdot 1$ under anaerobic conditions in the presence of glucose.

The second process seen in both colonies grown with and without glucose was assumed to be the oxidative deamination of amino acids, leading to ammonia accumulation. This was also reported by Coombs \& Wimpenny (1982), with values in aerobic regions of a gel model up to about pH 7.9. It is suggested that similar processes occur in the growing colony. When the cells are growing in the presence of glucose anaerobically and even aerobically, because of catabolite repression, organic acids are produced by fermentation pathways. Catabolism of glucose as a ready source of energy means that there is little need for the oxidative deamination of amino acids, hence reducing alkali production from this source and reducing the overall increase in $\mathrm{pH}$ measured around the colonies grown on glucose.

The method described for constructing the microelectrodes was easily mastered, requiring less skill than the methods used to make microelectrodes with glass as the ion-selective membrane (Thomas, 1978). It took half a day to prepare a batch of twelve pieces of glass and a further fifteen minutes to fill an electrode prior to use. Electrodes with small tips, especially those less than $3 \mu \mathrm{m}$ in diameter, were very sensitive to any movements made by the operator, despite being used inside a Faraday cage. The high noise-to-signal ratio was the main fault of the system. The wide range of ion-exchangers that are available means that with this technique it is possible to construct microelectrodes to detect a wide range of ions such as $\mathrm{Na}^{+}, \mathrm{K}^{+}, \mathrm{Ca}^{2+}$ and $\mathrm{NH}_{4}^{+}$.

The microelectrode techniques described are appropriate for measurements in any microbial system displaying spatial heterogeneity. Such systems include 
biofilms as found on teeth (dental plaque), slime on water pipes or on submerged rocks, immobilized cells or sediments. Certain food systems also lend themselves to investigation by microelectrodes. Gradients of $\mathrm{pH}$ may be expected through foods preserved in an acid solution, e.g. pickled vegetables. Gradients could also occur through mould ripened foods such as soft cheeses (Brie, Camembert, Stilton) or salamis such as Milano (T. P. Robinson \& J. W. T. Wimpenny, unpublished data). The growth of the mould on the exterior of these foods may cause deamination of amino acids and an increase in $\mathrm{pH}$. Additionally in fermented foods like salami, tempe or kefir grains, a more complex $\mathrm{pH}$ profile might be expected due to the heterogeneous structure of the food.

We would like to thank the Ministry of Agriculture, Fisheries and Food, and the Campden Food and Drink Research Association for supporting this work.

\section{References}

Bertl, A., Felle, H. \& Bentrup, F.-W. (1984). Amine transport in Riccia fluitans. Cytoplasmic and vacuolar $\mathrm{pH}$ recorded by a $\mathrm{pH}-$ sensitive microelectrode. Plant Physiology 76, 75-78.

Brown, J. P., Huang, C. T., Oldershaw, M. D. \& Bibby, B. G. (1981). Continuous measurement of plaque $\mathrm{pH}$ in vitro. Journal of Dental Research 60, 724

Caldwell, P. C. (1954). An investigation of the intracellular $\mathrm{pH}$ of crab muscle fibres by means of micro-glass and micro-tungsten electrodes. Journal of Physiology 126, 169-180.

COOMBS, J. P. \& WIMPENNY, J. W. T. (1982). Growth of Bacillus cereus in a gel-stabilized nutrient gradient system. Journal of General Microbiology 128, 3093-3101.

Cooper, A. L., Dean, A. C. R. \& Hinshelwood, C. (1968). Factors affecting the growth of bacterial colonies on agar plates. Proceedings of the Royal Society B171, 175-199.

HINKE, J. A. M. (1959). Glass microelectrodes for measuring intracellular activities of sodium and potassium. Nature, London 184, 1257-1258.

Jones, D., Pell, P. A. \& SNeath, P. H. A. (1984). Maintenance of bacteria on glass beads at $-60^{\circ} \mathrm{C}$ to $-76^{\circ} \mathrm{C}$. In Maintenance of Microorganisms, pp. 35-40. Edited by B. E. Kirsop \& J. J. S. Snell. London: Academic Press.

JøRGENSEN, B. B. \& REVSBECH, N. P. (1983). Colorless sulfur bacteria, Beggiatoa spp. and Thiovulum spp., in $\mathrm{O}_{2}$ and $\mathrm{H}_{2} \mathrm{~S}$ microgradients. Applied and Environmental Microbiology 45, 1261-1270.
Jørgensen, B. B., Revsbech, N. P. \& Cohen, Y. (1983). Photosynthesis and structure of benthic microbial mats: microelectrode and SEM studies of four cyanobacterial communities. Limnology and Oceanography 28, 1075-1093.

KaMATH, R. S. \& BUNGaY, H. R. (1988). Growth of yeast colonies on solid media. Journal of General Microbiology 134, 3061-3069.

Nelson, D. C., Jørgensen, B. B. \& Revsbech, N. P. (1986). Growth pattern and yield of a chemoautotrophic Beggiatoa sp. in oxygensulphide microgradients. Applied and Environmental Microbiology 52 , 225-233.

Peters, A. C., Wimpenny, J. W. T. \& Coombs, J. P. (1987). Oxygen profiles in, and in the agar beneath, colonies of Bacillus cereus, Staphylococcus albus and Escherichia coli. Journal of General Microbiology 133, 1257-1263.

PIRT, S. J. (1967). A kinetic study of the mode of growth of surface colonies of bacteria and fungi. Journal of General Microbiology 47, 181-197.

RevsBech, N. P. \& JøRgensen, B. B. (1986). Microelectrodes : their use in microbial ecology. In Advances in Microbial Ecology, vol. 9, pp. 294-357. Edited by K. L. Marshal. London: Plenum Publishing Corporation.

REVSBECH, N. P. \& WARD, D. M. (1984). Microelectrode studies of interstitial water chemistry and photosynthetic activity in a hot spring microbial mat. Applied and Environmental Microbiology 48, 270-275.

Rieck, V. T., Palumbo, S. A. \& Witter, L. D. (1973). Glucose availability and the growth rate of colonies of Pseudomonas fluorescens. Journal of General Microbiology 74, 1-8.

ShAPIRo, J. A. (1984). The use of Mudlac transposons as tools for vital staining to visualize clonal and non-clonal patterns of organization in bacterial growth on agar surfaces. Journal of General Microbiology 130, $1169-1181$.

ShaPIRo, J. A. (1987). Organization of developing Escherichia coli colonies viewed by scanning electron microscopy. Journal of Bacteriology 169, 142-156.

SPIRA, W. M. \& Silverman, G. J. (1979). Effects of glucose, pH, and dissolved oxygen tension on Bacillus cereus growth and permeability factor production in batch culture. Applied and Environmental Microbiology 37, 109-116.

ThомаS, R. C. (1978). Ion-sensitive Intracellular Microelectrodes. London: Academic Press.

WALKER, J. L. (1971). Ion specific liquid ion exchanger microelectrodes. Analytical Chemistry 43, 89A-93A.

Weimer, P. J. (1984). Control of product formation during glucose fermentation by Bacillus macerans. Journal of General Microbiology 130, 103-111.

WimpenNy, J. W. T. \& Coombs, J. P. (1983). Penetration of oxygen into bacterial colonies. Journal of General Microbiology 129, 12391242.

WimpenNy, J. W. T. \& Lewis, M. W. A. (1977). The growth and respiration of bacterial colonies. Journal of General Microbiology 103, 9-18. 